\title{
Devolution, independence, and the optimal provision of public goods
}

\author{
J.E. Stiglitz ${ }^{1}$ \\ Columbia University, United States
}

\section{A R T I C L E I N F O}

\section{Article history:}

Received 13 May 2015

Accepted 13 May 2015

\begin{abstract}
A B S T R A C T
This paper examines whether two regions should remain together within a fiscal federation, or separate, when their inhabitants have different preferences for publicly provided goods. The paper focuses on trade-offs between returns to scale in the provision of the goods, and the scope to tailor provision to the tastes of the inhabitants in each region. A general model is developed that includes, as special cases, both pure public and publicly provided goods, and regional and national public goods. We show that when there is a choice between public investment and consumption goods, there will, in general, be a bias against public consumption goods unless taxing powers are fully devolved. We provide conditions under which independence may be desirable even when the region contemplating independence is relatively small.
\end{abstract}

(c) 2015 Published by Elsevier Ltd.

\section{Introduction}

It is a real pleasure for me to contribute this paper in honor of Richard Arnott. Richard studied with me at Yale, and then went on to become a friend and co-author. We did work together in a wide range of areas, in labor markets and the economics of information; in public economics and urban economics, publishing 14 papers over a span of approximately 15 years (listed in the appendix). When I went to work in the Clinton Administration, we were working on a book on the general theory of moral hazard, putting together our many results in this field and extending them. That book, unfortunately, never got finished.

The papers that we wrote together are among my favorites. Our paper providing the basic analytics of moral hazard (Arnott and Stiglitz, 1988), showing the inherent non-convexities which arise in the presence of moral hazard, provides the simplest and best exposition of the concepts and analytics of moral hazard. Our subsequent use of that apparatus to show the Pareto inefficiency of markets with moral hazard not only provides an elegant and simple way of seeing why markets with asymmetric information are, in general, inefficient, but has provided a framework which has been subsequently used extensively in the analysis of macro-economic externalities (Arnott, Greenwald and Stiglitz, 1994).

In this paper, I wish to take up a theme that combines two of our interests - in public finance and in externalities. Much of our

\footnotetext{
${ }^{1}$ Financial support from the Institute for New Economic Thinking and the Inequality Project at Roosevelt Institute, supported by the Ford and McArthur Foundations, is gratefully acknowledged, as is research and editorial assistance from Sandesh Dhungana and Feiran Zhang. I have also found invaluable discussions with Alex Salmon, First Minister of Scotland prior to the 2014 referendum, and Gary Gillespie.
}

work has been concerned with externalities - where, for instance, the provision of insurance by one company affects the risks faced by other companies or where the provision of insurance against one risk affects the likelihood of another risk occurring (Arnott and Stiglitz, 1990).

As global warming has reminded us, externalities are both pervasive and of first order importance. They are essential in understanding the structure of metropolitan regions - the fact that there are pervasive and important has long been understood to be central to the organization of municipal governance; fragmented governance results in highly suboptimal outcomes. But there may be important trade-offs - Tiebout (1956) argued that there are efficiency benefits from competition among local communities, though the conditions under which such competition results in efficiency (let alone the maximization of an inequality averse social welfare function) are highly restrictive (Stiglitz, 1977, 1983a, 1983b).

Similar issues arise in the analysis of federalism. Recently, Scotland had a referendum about whether to become independent (again, because it was not until 1707 that it merged with England, in a process that has been described as highly corrupt. See Bowie, 2007). Those opposed to independence suggested that there were economies of scale and scope that would be lost as a result of independence, and that as a result, an independent Scotland would be poorer.

Unlike other independence movements, those arguing for independence were not nationalistic, though they typically argued that independence would strengthen their sense of national identity and social cohesion. Some recent work in economics argues that there can be significant economic benefits from social cohesion ${ }^{2}$.

\footnotetext{
${ }^{2}$ See, for instance, (Algan and Cahuc, 2013; Easterly et al., 2006).
} 
But other arguments were central for the advocates of independence. The first was that independence would allow a more effective expression of preferences with respect to public goods. There was a general consensus that preferences towards public goods in Scotland differed markedly from those in England. With Scotland being less than 10 per cent of the UK, the structure of public expenditures and taxes would inevitably be dominated by England. ${ }^{3}$

Those in England argued that devolution could solve the problem. Complete devolution, of course, is independence. The distinction between devolution and independence then depends on the set of responsibilities and powers that are not devolved. Typically, foreign policy is one example of a power that is almost never devolved.

This paper provides a simple model showing the conditions under which, in spite of economies of scale that are inherent in the provision of public goods, devolution is nonetheless desirable; and this may be true even if the country seeking devolution is small. What is critical is the relationship between the differences in preferences between the area seeking devolution and the rest and the magnitude of the scale economies. But it goes further in arguing that it may not be desirable to just devolve authority over the allocation of expenditures. There has to be at least some independence in tax authority.

In many instances of fiscal federalism, there is both some devolution of expenditure and tax authority. But the model presented here goes further: if the central authority derives any income from the taxation of income or property within the region with devolved power, the decisions with respect to the allocation between public consumption and investment will be distorted. While independence would remove this distortion, we do not address the broader question of whether there are politically feasible ways of dealing with the distortion short of independence.

Debates about devolution and the opposite - delegating some rights to a supra-national power, e.g. the EU or an international trade agreement - illustrate that there are an array of responsibilities and constraints that can be designed in a myriad of ways. With block grants, sub-national units can choose what to spend money on (within a specified range), but they still may not have the power to tax. With trade agreements, countries have access to all the economies of scale and scope in private production. But such agreements typically circumscribe the ability of the individual country to impose regulatory regimes that might reflect the country's preferences and judgments about risks.

This paper, motivated in part by the Scottish devolution debate, focuses on a context in which the political entities will be part of a common trading area even if devolution occurs, so there are no implications for the production and distribution of private goods. The focus is only on the choice of the level and kinds of public goods to be provided. We focus, in particular, on the institutional arrangement proposed at the time, where there was devolution of the power to allocate expenditures among different publicly provided goods, but the power to tax (largely) remained centralized. But devolution of expenditure allocation without full devolution of taxation presents a problem: the returns to investments (e.g. in education, industrial policies, infrastructure) are not fully captured because the revenues from investment are shared between regions. This is particularly true for a small country, like Scotland: the bulk of at least the tax benefits go to others. There is thus a bias against investment.

Full devolution of taxing power, on the other hand, undermines one of the critical arguments for federation: redistribution. (Indeed, part of the basis of many independence movements is that richer regions wish to avoid the redistribution that results from their being

\footnotetext{
${ }^{3}$ Differences in patterns of expenditure between Scotland and England have long historical and cultural roots, with greater access to education and substantially lower university tuition in Scotland than in England (see Herman, 2001).
}

part of a larger federal system. But with Scotland and Quebec arguably poorer than the rest of the country, this was not part of the motivation for their independence movements.)

This paper builds on a considerable literature examining the formation of political entities - both the Nash equilibrium and the optimum. To simplify the analysis, we abstract from issues of distribution by assuming that incomes are identical. Part I provides a brief overview of that literature, clarifying the different dimensions of economies of scale and scope which have played an important role in earlier discussions. Part II focuses on the limitations of devolution of expenditures in the absence of devolution of taxation.

\subsection{Toward a more general theory of devolution}

In Section 2, we describe the basic determinants of the formation of political entities and some of the key results in the earlier literature, while Section 3 extends the analytics.

\section{The basic determinants and some key results}

Both economic and political considerations enter into the decisions concerning the number of political entities and the relationship among political entities - the extent of devolution. The strong economic forces leading to large entities with limited devolution are related to returns to scale often associated with public goods, and the difficulties of internalizing cross-border externalities. Two of the important forces militating for smaller entities are diseconomies of scale (congestion costs, increasing costs of managing large political entities) and diversity of preferences. In many ways, the issues are parallel to those in the theory of the firm, and indeed, some of the literature below explicitly draws upon that analogy. In the absence of diversity of preferences, the optimal scale of the firm (in a world with a large enough population) is that which minimizes average costs where the (marginal) benefits of increasing scale are just equal to the marginal costs. With diversity of preferences, there is a trade-off between a lower average cost of production and the ability to better match preferences, the central issue in the theory of monopolistic competition. ${ }^{4}$

In the case of political entities, there are further political considerations: there are intrinsic problems in preference revelation for public goods, and some have argued that smaller jurisdictions may be able to make decisions more reflective of the preferences of their citizens ${ }^{5}$. Moreover, political entities often engage in significant redistribution among different groups. Those who believe that they are being exploited have an incentive to establish their own political entities. In principle, the "exploiters" should limit their exploitation to levels where the losses from not being part of a larger entity (benefiting from the returns to scale) just induce the group contemplating succeeding not doing so. Finally, as we comment in the concluding section of this paper, there are issues of national identity that influence some groups to want to have their own entity - even if the economic costs of doing so, at least as reflected in standard approaches, are significant. In this paper, we largely ignore these political considerations, though we note that certain political constraints (e.g. in the extent of tax discrimination) may play an important role in determining the formation of political entities.

\footnotetext{
${ }^{4}$ See e.g. () building on the fundamental work of Hotelling (1929). In some formulations, such as Dixit and Stiglitz (1977) individuals care about having a diversity of goods. One can have more goods, but only at the cost of a higher average cost of production for each.

${ }^{5}$ Agency costs may be smaller.
} 


\subsection{The basic components to the analysis}

In this section, we provide a broad framework, which encompasses most earlier analyses as special cases, within which we can assess the importance of the economies and diseconomies of scale.

\subsubsection{Technology}

The literature on the formation of political entities has implicitly focused on three properties of the technology of publicly provided goods: (a) the magnitude of the marginal cost of delivering the good to an additional individual; (b) the magnitude of the marginal cost of expanding the geographical provision of the publicly provided good; and (c) the costs associated with increasing the variety of public goods, e.g. tailoring the provision of the goods to differences in tastes.

Thus, the cost function $E^{i}$ (i.e., expenditure) of providing a quantity of public good $i, G^{i}$, depends on the number of individuals served, $m^{i}$, the number of locales (regions) served, $\mathrm{n}^{\mathrm{i}}$, and the variety of "designs" with which it is provided, $v^{i}:{ }^{6}$

$E^{i}=\psi_{i}\left(G^{i}, m^{i} \cdot n^{i}, v^{i}\right)$.

In this formulation, a defining characteristic of the publicly provided good is that the quantity provided to all individuals is the same. A simple parametric form is

$E^{i}=G^{i}\left(m^{i}\right)^{\beta}\left(n^{i}\right)^{\gamma}\left(v^{i}\right)^{\sigma}$

Much of the literature has focused on certain limiting cases. Samuelson (1954) considered a pure public good with zero marginal cost of providing the good to an additional individual regardless of his location and with one variety, i.e. $\gamma=0, v^{i}=1$, and $\beta=0$, so

$E^{i}=G^{i}$.

Many publicly provided goods, like education and health, are close to publicly provided private goods where there are no economies of scale - the marginal cost of providing the service or good to an additional individual is close to the average cost. (One might ask, if these are really private goods, why are they publicly provided? There is a large literature answering this question, related to market failures, the benefits of enhancing social cohesion through publicly provided education, and ensuring the attainment of basic rights, such as the access to health care. These are important issues, but take us beyond the scope of this paper. ${ }^{7}$ )

Stiglitz (1974) considered this case of publicly provided private goods, again in one locale and with one variety, so that $\gamma=0, v^{i}=1$, and $\beta=1$ and the cost function then becomes

$E^{i}=m^{i} G^{i}$

Atkinson and Stiglitz (1980) look at the full range, from Samuelsonian public goods to publicly provided private goods, i.e. $\gamma=0, v^{i}=1$, and $0 \leq \beta \leq 1$.

As we noted, for Samuelsonian public goods, the marginal cost of provision to any individual is zero regardless of location. Tiebout (1956) and Stiglitz (1977) consider local public goods, the benefits of which can be extended beyond the community only at very high costs. Fire departments and local police protection are examples of local public goods. Consider for simplicity the symmetric case where all communities are of the same size and the public good is provided in one variety. Then the cost function for a Samuelsonian

\footnotetext{
${ }^{6}$ This obviously greatly simplifies. We should specify the number of individuals in each region, the number of varieties offered to each individual and provided in each region, etc.

${ }^{7}$ Many are, in fact, closely associated with inequalities in income and wealth, which we are explicitly not addressing in this paper.
}

local public good provided to $\mathrm{n}$ locales is

$E^{i}=n G^{i}$,

that is $\gamma=1, v^{i}=1$, and $\beta=0$. In the polar opposite case of locally provided pure private goods, it is plausible that the cost function will be as in (2.2b), where $m^{i}$ is the total number served in all communities. But there may be fixed costs of delivering even private goods to different communities, so that costs increase both with the number of individuals served and the number of individuals served. $^{8}$

Once one recognizes the territorial dimension of public goods ${ }^{9}$, the analysis can be extended down or up. Stiglitz (1995) focused on international, or global, public goods, the benefits of which could be extended to anyone living anywhere in the world with no marginal costs. Knowledge is an obvious example of a global public good, as is global warming. ${ }^{10}$ One could easily formulate models in which the costs of extending the geographical reach of the public good ranged from zero to infinity.

Different individuals have preferences for goods with different characteristics, and such preferences may systematically differ across regions. In some cases, it may be easy to alter the characteristics of the goods to reflect differences in preferences (assume, for instance, that there were differences in preferences for the kinds of trees or flowers in parks), i.e. $\sigma=0$. In other cases, there may be significant costs in providing goods with different characteristics - if the costs of the public good are basically fixed costs, the costs may increase with the number of varieties provided, i.e. $\sigma=1$. In still other cases, it is only feasible to have one variety - a country can have only one defense/ offense posture; this can be captured by assuming that $\sigma$ is infinite. ${ }^{11}$

\subsubsection{The economic environment}

There are four critical characteristics of the overall economic environment that affect the formation of political entities: (a) the existence of congestion, or other sources of diseconomies of scale; (b) diversity of tastes; (c) limits on the size of the overall population; and (d) the extent of mobility of individuals.

The technological characteristics described in the previous paragraphs describe the nature of the returns to scale. Economies of scale provide the rationale for having large communities. The existence of congestion and the presence of large differences in tastes explain some of the reasons that one may want to limit the size of a community or nation. Limits on the size of the overall population in the presence of diversity of tastes provides one of the reasons that there may be communities with diversity of preferences. (With congestion costs, there will typically be an optimal size of the community; with an arbitrarily large population and a finite number of types of individuals, then so long as individuals do not differ in their productive capacities, there will be homogeneous preferences within communities.)

Tiebout argued that with mobility, there was a further significant advantage from having a large number of competing communities: competition among communities would ensure efficiency and provide the basis of preference revelation - individuals would choose the community to live in which best matched their preferences, thus resolving the longstanding issue in the theory of public goods of

\footnotetext{
${ }^{8}$ that is, $E^{i}=m^{i} G_{i}+\zeta n^{i}$ where $\zeta$ is the fixed cost of serving a community.

9 It should be clear that society can be divided in other ways, besides geography, and there may be marginal costs of providing goods to different groups This may be particularly important when there is an attempt to "tailor" public goods to differences in preferences.

10 See (Stiglitz, 1999) for a discussion of knowledge as global public good, and Stiglitz (1998) for a discussion of international financial institutions as global public goods. For broader discussions, (see Kaul et al., 1999; Stiglitz, 2007)

${ }^{11}$ There is an alternative formulation, in which each variety of public good is treated as a separate good, and there can be economies or diseconomies of scope in production.
} 
preference revelation. As Oates (1999) points out, and as the above discussion should have made clear, there are other reasons both for delegating the provision of certain public goods to local jurisdictions and other reasons for having multiple political jurisdictions.

Tiebout never showed that Tiebout competition would result in Pareto efficiency, and it turns out that the conditions under which that is the case are highly restrictive (). For instance, if there are a finite number of communities, even if that number is large, competition among communities is much like monopolistic competition. And it is well-known that only under very restrictive conditions is the equilibrium with monopolistic competition Pareto efficient. ${ }^{12}$ Later, we will illustrate more precisely the nature of some of the inefficiencies which arise.

But the presence of these inefficiencies provides an important rationale for not decentralizing and not forming separate political entities: actions by one political entity (or those within one entity) may exert externalities on others. In principle, with a central political authority, those externalities could be internalized, and a Pareto superior outcome achieved.

\subsubsection{Political constraints}

But whether those externalities are effectively addressed depends on still one more set of key variables determining the desirability of creating independent entities: the nature of the political processes. In systems of majority voting, for instance, the majority may pay little attention to the preferences of the minority, or may even exploit them. A natural response is for the minority to secede. The threat of secession itself can change the outcome. The Constitution of Ethiopia included a provision which allowed regions to vote to secede. It was put there because those who had succeeded in overthrowing the Derg regime, disproportionately from a minority region (Tigray) which felt that it had long been oppressed by those from the region surrounding the capital Addis Ababa, wanted to prevent such abuses from occurring in the future. But they had not fully anticipated that a region might vote to secede not because it had been oppressed, but simply as an expression of national identity, or because politicians, wanting greater political power for themselves, might successfully persuade citizens that they would be better off with secession - even if there were significant economies of scale which would have called for the country remaining united.

Modeling constraints on the political process is not easy; but there is an important literature showing how different political structures affect the supply of public goods (see, e.g. Lizzeri and Persico, 2001; Persson et al., 2000; Qianand and Roland, 1998), and therefore presumably the desirability of devolution or the creation of independent political entities. While some claim that moving decision making closer to the people - devolution and creating separate political entities - makes government more responsive, the public good is a public good - i.e. there may even be scale returns in governance itself, so that civil society representing the interests of ordinary citizens may be more effective in larger political bodies. Indeed, in the United States, much of conflict over delegation of decision making to states revolves around differences in "voice" of different groups at different levels, which can be especially important when there are significant differences in deviations for majoritarian decision-making at different levels. Rural and corporate interests often tend to be more influential at the state level. ${ }^{13}$

The existence of political constraints - including constraints on the ability to make commitments and to differentiate among different individuals (individuals at different locations) $)^{14}$ - is in many ways

\footnotetext{
12 Stiglitz (1986a) and Dixit and Stiglitz (1977).

${ }^{13}$ For a more extensive discussion of decentralization issues in the context of development (see Faguet and Pöschl, 2015).

14 The discussion above provides part of the explanation for limitations in the ability to differentiate the provision of goods to different regions/locales/
}

pivotal to the analysis. For in the absence of such constraints, presumably there would be no reason to establish separate political entities. A centralized entity could always decentralize (engaging in optimal fiscal federalism), internalizing all the externalities, balancing off optimally the economies of scale and scope with the diseconomies arising from congestion and preference diversity; but at the same time, it could internalize all the externalities. ${ }^{15} 16$

In this paper, we will abstract from these important considerations, simplifying the analysis to assume majority rule and constraining the government's ability to differentiate tax treatment of different individuals. The later analysis will make clear why this constraint is important.

There is one further important aspect of fiscal federalism: as we have already noted, government typically provides an array of public goods, financed by an array of taxes. Typically, there is some devolution of some decision making with respect to the provision of some public goods and services and the levying of some taxes, but not of others. Independence can be thought of as the limiting case where there is devolution of all goods and services and taxes - with no constraints imposed at the national level. (That, of course, does not mean that there cannot be cooperation and coordination, e.g. to address cross-border spillovers; even if externalities are not perfectly addressed, they need not be ignored.)

Typically, there is considerable devolution of education and health, and none of defense and foreign policy. Even the advocates of independence often grant that there may be some benefits to the provision of some "national" public goods at the national/ federal level, but that the disadvantages of non-devolution in the case of others exceed these benefits. Again, in the analysis below, we will ignore these complexities, but will focus (in Part II) on one central aspect of independence vs. devolution: so long as there is a national income tax, under devolution, there will be distortions in the choice between public investment and consumption goods.

\subsection{Some general results}

In the previous subsection, we described the crucial ingredients in our analysis - technology, the economic environment, and political constraints. Results are highly contingent on the specific assumptions made with respect to each. Many of those most widely discussed represent special cases, as we shall see.

\subsubsection{Some simple limiting cases}

Most of the literature on the formation of public entities has focused on certain limiting cases. For instance, in the absence of congestion or diversity, with a pure public good, there should be only one community; and the same would be true even if there is diversity of preferences, if there are no costs to providing the

\footnotetext{
(footnote continued)

individuals: the nature of technology means that there may be substantial costs in doing so. There is an optimal degree of differentiation. But this does not provide a full explanation, especially in the case of publicly provided private goods. Concerns about fairness, of ensuring that no one is treated better than another - when it is difficult to assess what is better - provide support for equality of provision. In the case of education, there are concerns about creating a sense of solidarity and building cohesion.

${ }^{15}$ In the context of production of private goods and the theory of the firm, Stiglitz(forthcoming) has referred to this as the Centralization Paradox, which is partially resolved by taking into account constraints on the ability to make commitments.

${ }^{16}$ One might be tempted to argue that in such an idealized world, Coasian bargaining could just as well result in an efficient outcome among a set of communities/nations of optimal size, provided that there was an appropriate assignment of property rights. But there would need to be a global political authority to assign such property rights. And even with such an assignment, in general Coasian bargaining does not achieve an efficient outcome, in the presence of transactions costs and/or information asymmetries.
} 
appropriate diverse mix of public goods $(\mu=0)$. But with a publicly provided private good, with no economies of scale, there is no reason to have a large community. Hence, if there are differences in preferences across local communities, there would be no reason not to form separate political entities for the provision of these goods.

\subsubsection{Optimal city sizes and the Henry George theorem}

There are some other limiting cases where the results are not so immediate. For instance, in the case of local public goods in economies with congestion (or other sources of decreasing returns to scale offsetting the increasing returns associated with the provision of a local public good), there is an optimal city size, with a number of authors independently obtaining the result that in that optimal city, what Arnott and Stiglitz (1979) refer to as the Henry George Theorem where expenditures on public goods equals land rents - holds. ${ }^{17}$ George (1879) had much earlier argued for the imposition of a land tax; this theorem showed that, in cities of the optimal size, such a land tax was the only tax that was required.)

Individuals may, of course, differ in their preferences between public goods and private goods, in which case those preferring more public goods will live in larger communities. Those within the community will have identical preferences; there will be unanimity about the spending on public goods.

This result, however, is not general.

\subsubsection{Diverse populations: diversity may not matter}

The previous result requires in particular that there be an arbitrarily large population to be divided at will among an arbitrarily large number of communities and that individuals with different complementary skills do not have different preferences. If there is an arbitrarily large population with different skills all of which are required in production (or, at least, which are complementary in production), then communities will compete for people with different skills. The attractiveness of a community to a worker with a particular set of skills will be determined by the set of public goods it provides and the wages. In this case, in general, there will again be communities of an optimal size, with again the size of the community depending on the extent of preferences for public goods (the balance between diseconomies of scale associated with congestion and economies of scale with public goods occurs at a larger population.) The equilibrium will be efficient.

Unlike the previous case, communities will consist of a diverse population. Plumbers and carpenters may have different preferences from bankers and doctors, but it is efficient for them to live together. But perhaps surprisingly, there is still unanimity: for each will take into account the effect of changing the mix of public goods on the supply price of labor with different skills (). Diversity need not be the basis of division.

\subsubsection{Diversity of preferences may matter: a model with a continuum of individuals}

Under more general conditions diversity matters, and it can matter even with a continuum of individuals and an infinite number of communities, even without congestion and joint production - if there is sufficient diversity of preferences, as the following model illustrates.

Assume there is a continuum of locations at which individuals may locate themselves (from minus to plus infinity), public goods are provided at the center of each city, and individuals have to pay

\footnotetext{
17 Many of these authors posed the question in slightly different ways (see, e.g. Serck-Hanssen, 1969; Starrett, 1974; Flatters et al., 1974; Vickrey, 1977). As Arnott (1998) observes, the results is quite robust. Arnott and Stiglitz (1979) go on to show that in their idealized model, expenditures on public goods are equal to one half of aggregate transport costs.
}

transport costs, equal to $\mathrm{kt}$ in traveling a distance $\mathrm{t}$ from their location to the city center. The equilibrium results in an infinite number of identical cities, separated by a distance, 2 T. Only one person can be located at each point. Land half way between two cities has a (differential) land rent of zero. Land at a distance $t$ from the city center rents for $R(t)$. In equilibrium, $R(t)=R_{o}-k t$, where $R_{o}=k T$, i.e. individuals are indifferent as to their location. We denote by $R^{*}$ total rents, and assume that rents are spent on the provision of public goods, with the excess of $G$, public expenditures, over $R^{*}$ being financed by a lump sum tax. Net income to be spent on private consumption goods, $C$, is

$C=Y-R(0)-\left(G-R^{*}\right) / 2 T$,

where $Y$ is the individual's income (all individuals are assumed to have the same income) $\mathrm{X} .{ }^{18}$ Total rents are then

$R^{*}=2 \int_{0}^{T} k t d t=k T^{2}$,

since rent at the boundary is $0^{19}$, while rent at the city center is

$R(0)=k T$.

Substituting (2.4) and (2.5) into (2.3), we obtain

$C=Y-G / 2 T-k T / 2$.

Hence for given $G, C$ is maximized when

$T^{2}=G / k$,

or using (2.4)

$R^{*}=G$,

the standard Henry George Theorem. Substituting (2.7) into (2.6) and simplifying, we obtain that in cities of the optimal size

$C=Y-(G k)^{1 / 2}$

so if the utility function for public and private goods is

$U=u(C)+\xi G$,

then $G$ is optimized when

$(1 / 2) U^{\prime}(k / G)^{1 / 2}=\xi$.

If public goods are more important relative to private goods (i.e. $\xi$ is larger), the optimal size of the community is larger, rents are larger, and government expenditures are larger.

This equilibrium is both Pareto efficient and is the utilitarian optimum. Indeed, each individual has the same level of utility since declining rents offset the costs of increased "distance" that an individual incurs as they locate further from the city center.

But in the product variety interpretation of the Hotelling model, it is not possible to identify precisely the preferences of each individual and therefore to eliminate the consumers' surplus associated with having the public good of a type which conforms to their preferences.

In this case, each individual has a preferred "type" of public good, defined again by their location on the line. There is a fixed cost of a public good of a particular type (which comes in a fixed size, normalized at unity). An individual whose preferred type is $\alpha^{*}$ has utility

$\mathrm{U}\left(\mathrm{C}, \mathrm{G}\left(1-\mathrm{k}\left|\alpha^{*}-\alpha\right|\right)\right)$,

\footnotetext{
${ }^{18}$ If $G<R^{*}$, the difference is distributed as a lump sum payment to individuals

19 When land is scarce, it may have a positive value for other users such as agriculture. It is only the differential rents at the boundary that are zero. Notice that in this linear city with linear transport costs, aggregate differential rents equal aggregate transport costs. This contrasts with Arnott and Stiglitz (1979) who analyze circular cities, in which case aggregate differential rents equal one half aggregate transport costs. As we note, the Henry George theorem obtains in either case.
} 
where again $C$ is his level of private consumption. But the utility he gets from each unit is reduced by the distance of the good from his preferred type, $\left|\alpha^{*}-\alpha\right|$. $k$ is a measure of the strength of his preference for his preferred type. The mathematics for the optimal spacing of communities/optimal number of communities follows along the lines of the previous case.

\subsubsection{Inefficient equilibria}

These limiting cases are misleading: in more normal circumstances there are a finite number of communities, and then, as we have noted, there is no assurance that even with perfect mobility, the equilibrium which emerges will be efficient.

Consider, for instance, a situation where there are $M$ individuals with diverse preferences, and there are two islands, call them the North and the South, indexed by $j$. Assume there is mobility across the islands, and that each island faces congestion costs. We simplify by assuming that the only way in which individuals differ is in the intensity of their preference for public goods. We assume further that all individuals have the same income, there is a lump sum tax $\tau^{j}$ on island $j$, and that individuals have a demand for land in the community in which they live that depends on the rental rate per unit of land, $r^{j}$. Individuals will divide themselves between the islands, with those with a stronger preference for public goods living on one island, which we assume to be the North. All land within an island is homogeneous, so the rent is the same.

Utility is a function of the public good, the private good, the rent per unit of land, $r$, and the congestion level

$U\left(Y-\tau^{j}, G^{j}, r^{j}, M^{j}\right), \quad j=N, S$.

Clearly

$M^{N}+M^{S}=M$

Equilibrium land rents on the two islands are such as to make the demand for land on each island equal to the supply. The marginal individual, who is indifferent between the islands, has a stronger preference for public goods than anyone (else) on $S$, and weaker preferences for public goods than anyone (else) on $N$. If $G^{N}$ increases, e. g. financed by an increase in a tax on landlords (while $G^{S}$ is fixed), then the marginal individual will shift from the South to the North, $r^{N}$ increases and $r^{S}$ decreases.

The government of island $\mathrm{j}$ chooses $G^{j}, \tau^{j}$, and the tax rate on rents on island $j, \tau_{R}^{j}$. Let $R^{j}$ denote the aggregate rents on island $j$. The public good is funded from revenues from the lump sum tax and rent taxes so that

$G^{j}=\tau^{j} M^{j}+\tau_{R}^{j} R^{j}$,

If we normalize the size of the land on each island at unity, $R^{j}=r^{j}$.

We focus on a Nash equilibrium, where each island takes the value of the policy variables of the other island as given. The choice of each island depends on the political system. Assume, for simplicity, that majority rule prevails on each island. In the absence of migration, and assuming, in equilibrium, the median voter neither is renting in or renting out land, so changes in $r$ have no effect on his well-being. ${ }^{20}$

$(\partial \mathrm{U} / \partial \mathrm{G})^{\mathrm{m}} \mathrm{M}=(\partial \mathrm{U} / \partial \mathrm{C})^{\mathrm{m}}$,

\footnotetext{
${ }^{20}$ Alternatively,we can assuming that changes in $G$ and $\tau$ do not affect the demand for land, so that in the absence of migration, these changes do not affect $r$. More generally, if an increase in $G$ (say financed by an increase in the lump sum $\operatorname{tax}$ ) increased $r$, and if the median voter was a renter, he would choose a level of $G$ smaller than indicated by (2.16).
}

where the superscript $m$ refers to the median voter. This is similar to the Samuelsonian condition that

$\Sigma_{j}(\partial U / \partial G)^{j} /(\partial U / \partial C)^{j}=1$,

i.e. that the sum of the marginal rates of substitution is equal to one. The two conditions would be the same if the marginal rate of substitution of the median voter was equal to the average marginal rate of substitution, i.e. if

$(\partial U / \partial G)^{m} /(\partial U / \partial C)^{m}=\left[\Sigma(\partial U / \partial G)^{j} /(\partial U / \partial C)^{j}\right] / M$

As is well known, ${ }^{21}$ whether

$\left(\Sigma(\partial U / \partial G)^{j} /(\partial U / \partial C)^{j}\right) / M>$ or $<(\partial U / \partial G)^{m} /(\partial U / \partial C)^{m}$

depends on the shape of the utility functions and the probability distribution of tastes. If, for instance, the utility function is separable in private and public consumption,

$U=u(Y-\tau ; r, M)+\xi v(G)$

where $\xi$ reflects the intensity of preferences for $G$, then if there is a symmetric probability distribution of $\xi$ around the median, then the mean and median marginal rate of substitution are the same. For simplicity, we will assume that that is the case, so that in the absence of migration, the majoritarian voting equilibrium is Pareto efficient. $^{22}$

There are three distinct effects of migration: on the political equilibrium, on rents, and on spending on public goods. The median voter would realize that by attracting in migration or encouraging outmigration, he changes his position as the decisive voter, and this will lead to choices that are less consistent with his preferences.

In-migration always results in more spending on the public good, $G$, because of the lump sum tax on individuals. (This assumes that $\tau^{j}>0$. If there is a lump sum subsidy, as in Alaska, the effect would be just the opposite.) The effect of rents on the well-being of the median voter can be either positive or negative. Making the island more attractive leads to an increase in rents. To the extent that rents are taxed to finance public goods, he benefits. If the median voter is not a landlord (renting out more land than he rents in) he benefits from in-migration; if he is not a tenant, he benefits from outmigration. In the normal case, we might expect the median voter to be net a tenant, and thus he would like his island to be less attractive to the marginal migrant.

The key point is that the extent of in or outmigration depends on the preferences of the marginal individuals, which in the North entails an individual who has weaker preferences for public goods than any of the (other) residents on the island, and in the South, a stronger preference for public goods.

Thus, in a renter-dominated political equilibrium, if the "rental effect" dominates, each island tries to make itself less attractive. The North has a higher (than Pareto efficient) level of $\tau$ and $G$, and the South a lower level. Mobility pushes the two islands apart. By contrast, in a landlord dominated equilibrium, just the opposite occurs.

These results can be seen more precisely in a simplification of the above model, where there are $M$ plots of land in each island, of fixed size, and an overall population of $2 M$, so that in equilibrium, precisely half the population lives on each. Though in equilibrium there is no migration, there is still competition for the lots on each island. The possibility of migration makes a difference. Under these assumptions, what individuals care about is the utility from

\footnotetext{
${ }^{21}$ See Stiglitz (1974) or any of the standard textbook treatments, such as Atkinson and Stiglitz (1980) and Stiglitz (1986b) and the references cited there.

${ }^{22}$ It should be obvious that there are conditions under which majority voting leads to too much or too little spending on public goods, relative to the Pareto efficient level.
} 
the consumption and public good, which in turn is affected by the total cost of living on the island, $F^{j}$

$F^{j}=\tau^{j}+r^{j}$

With $\{F, G\}$ on one island fixed, the amount that the marginal individual is willing to pay to live on the other island is given by

$U^{\mu}(Y-F, G)=U^{*}$

where the superscript $\mu$ refers to the marginal resident, and $U^{*}$ is his utility on the first island. An increase in the lump sum tax just comes out of the rents that individuals pay. An increase in $G$ implies that the marginal migrant is willing to pay more to live in the community. He remains indifferent so long as

$\partial F / \partial G=(\partial U / \partial G)^{\mu} /(\partial U / \partial C)^{\mu}$.

Consider the North, and assume it chooses $G$ to maximize net rents, MF-G. Then

$M(\partial U / \partial G)^{\mu} /(\partial U / \partial C)^{\mu}=1$.

Because the marginal individual values the public good less than the average, it is clear that

$M(\partial U / \partial G)^{\mu} /(\partial U / \partial C)^{\mu}<\Sigma(\partial U / \partial G)^{j} /(\partial U / \partial C)^{j} / M$,

and there will be an undersupply of the public good in the North. By the same reasoning, there will be an oversupply in the South.

On the other hand, in the North if the median voter owns no land, then so long as $G<\mathrm{MF}$, he will vote for a higher level of $G$, even though that results in a higher value of $F$, as land rents get bid up

$(\partial U / \partial G)^{m}-(\partial U / \partial C)^{m}\left((\partial U / \partial G)^{\mu} /(\partial U / \partial C)^{\mu}\right)>0$.

Thus, the equilibrium level of $G$ is the solution to

$U^{\mu}\left(Y-G^{*} / M, G^{*}\right)=U^{*}$.

With this value of $G$ and the associated taxes, the individual who least prefers public goods is indifferent between living in that community or moving to the low tax, low public good community. There will be an oversupply of public goods in the North (relative to the Pareto efficient level), and by the same reasoning, an undersupply in the South.

We have thus seen that competition among communities, when there is mobility, can lead to either a centrifugal or centripetal force, moving the communities further apart or closer together, depending on the nature of the political process (whether landlords or renters dominate in the political equilibrium.) But even when the political equilibrium would have resulted in a Pareto efficient allocation without migration, it will not do so with migration. When there are a finite number of communities and migration, each worries about how its political decisions will affect migration and rents, with landlords wishing to maximize (net of taxes) rents and renters wishing to reduce rents.

Even if the government within each country were to pursue a policy which was Pareto efficient for its citizens, it would balance out the adverse congestion effect with the net benefit to the community of the additional tax revenues and rent payments not taking into account the adverse effects of these policies on the other community.

In short, whenever there is mobility, there are cross-border externalities. With integration, these externalities could be internalized. But integration itself will affect the political equilibrium. Whether the compensations which would be required to make sufficient numbers in each of the islands support integration are feasible, and whether such compensations could be sustained in the integrated political equilibrium, are questions that would take us beyond this short paper.

\section{The desirability of devolution: static analysis}

In this section, we explore the desirability of devolution/ separation in a one period model in the context of a world in which there are only two regions, denoted North and South. We will see that there are some conditions under which separation is never optimal - a pure Samuelsonian public good, where the only differences in preferences related to the level of expenditures on the public good, and in which discriminatory taxation is feasible; and there are other conditions under which separation is always desirable - in which the public goods are all publicly provided private goods, in which there are no economies of scale in production, and there are differences in tastes both with respect to scale and "type." Most cases, of course, lie between these two extremes, which is why the issue of separation/independence is often so difficult.

\subsection{Differences only in the level of provision of the publicly provided good}

Assume there are two regions of equal size with consumers who value private goods consumption $C$ and public goods consumption " $G$ ". In the first subsection, we will assume that the citizens of the two regions differ only in the intensity with which they prefer the public good. In the following section, we will also assume they differ in the form of their preferred public good.

We assume that everyone in the two regions has the same income, $Y$, that the public good is financed by a uniform tax on individuals in the two regions of equal population, $M$, so consumption of the private good is $Y-G / 2 M$, and utility in region $i$ is

$V^{i}=V^{i}(Y-G / 2 M, G)=v^{i}(G, 2 M)$.

For a fixed $M, v$ is an inverted $U$ shaped function of $G$, as depicted in Fig. 1 , attaining a maximum at $v^{N *}$ at $G^{* N}(2 M)$. Assume those in community $\mathrm{N}$ (for North) prefer more public goods to those in community $S$ (for South), so that $G^{* N}(2 M)>G^{* S}(2 M)$ for all $M$. If community $\mathrm{S}$ is in the majority, community $\mathrm{N}$ must decide whether to go it alone, i.e. whether

$v^{N}\left(G^{*} S(2 M), 2 M\right)<v^{N}\left(G^{*} N(M), M\right)$

As the figure illustrates, this is possible. If there are large differences in preference, then the North would rather go it alone.

Of course, the South should realize that if (3.2) is satisfied, then $\mathrm{N}$ will vote to secede. Hence, it has to ascertain if there is a value of $G$ such that

$v^{S}(G, 2 M)>v^{S}\left(G^{*} S(M), M\right)$

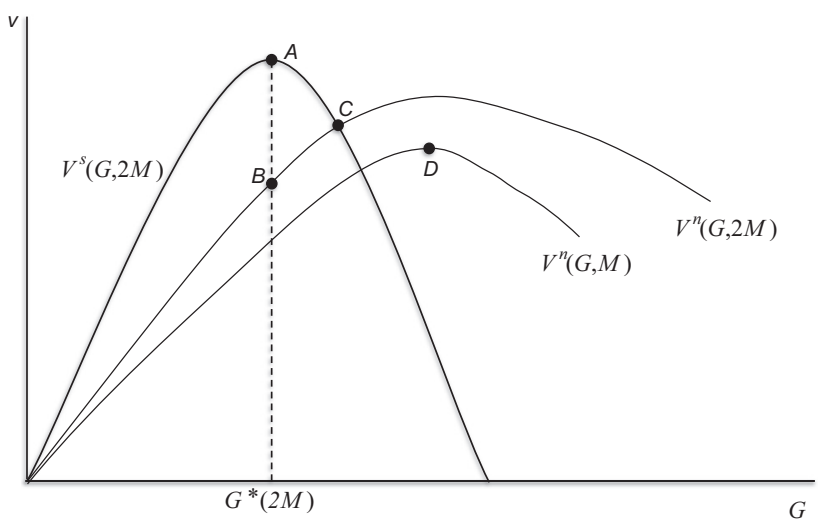

Fig. 1. In the federation, with the South determining the equilibrium level of public goods, the utility of the North, at the value of $G$ chosen by the South, is lower than the utility that the North could get by going it alone. 
and

$$
v^{N}(G, 2 M)>v^{N}\left(G^{*} N(M), M\right)
$$

That is, both the South and North are better off staying together and compromising on $G$. There is a critical value of $G, G \mid$ widehat $^{S}$ such that if $G^{* S}<G<G \mid$ widehat $^{\mathrm{S}}$, (3.3) is satisfied, and a critical value of, $G \mid$ widehat ${ }^{N}$ such that if $G^{* N}>G>G \mid$ widehat $^{N}$ then (3.4) is satisfied. With $S$ in the majority, $G$ will be chosen so that

$v^{N}(G, 2 M)=v^{N}\left(G^{*}(M), M\right)$,

That is, $G$ is the lowest level such that the North is indifferent to seceding or not. As Fig. 2 makes clear, with very large differences in preferences, there may not exist such a $G$, i.e. $G \mid$ widehat $^{S}<G \mid$ widehat $^{N}$.

But note that if there can be discrimination in taxation, secession is never desirable. Assume, for instance, that the tax rate on the South is set so that $T^{S}=G^{* S}(M)$, and that on the North is

$T^{N}=G-G^{*} S(M) / M$

Let $v^{N d^{*}}$ be the maximized value of utility under this discriminatory tax regime ${ }^{23}$. It should be clear that $v^{N d^{*}}>v^{N}(M)$ and those in the South are better off as well (since $G$ has increased, with no increase in taxes.) In the case of pure Samuelsonian public goods, where the only difference across communities lies in the amount of the good to be consumed, there is always a unitary government that dominates, provided discriminatory taxation is possible. It is Pareto superior to secession. But in practice, it is often not - partly because it is often difficult to ascertain true preferences, and there is a bargaining problem with information asymmetries; such bargaining is often characterized by a breakdown.

It should be obvious though that this strong result holds only in the case of pure public goods. If there are no economies of scale in production, i.e. what is being provided is a publicly provided private good, like education or health, then when there are differences in tastes, there is no reason to maintain the unitary government. ${ }^{24}$

\subsection{Differences in preferences over characteristics of the public goods}

But these results depend critically on individuals differing only in their preferences with respect to the level of consumption of the public good. But as we noted earlier, individuals in the two communities may differ as well in the characteristics of the public good that they prefer. And of course, if that is the case, the desired level of consumption will depend on the characteristics of the public good provided. Here, we focus on the case where the public good can only be provided in one "type", i.e. a military force that is either aimed at defense or at offense.

This example illustrates a situation where some forms of expenditure may actually have a negative "benefit" for some individuals. While the "public good" - the invasion of Iraq - may have increased the well-being of some citizens (those who enjoy seeing their country dominate others, or who feel more secure knowing that their country can do so), it may have decreased that of others (those who feel that force should only be used in extreme circumstances, that there should be an international rule of law, and who feel deeply about their country violating agreed principles of international law, at least as they see it.)

We generalize (3.1) by introducing a preferred characteristic of the public good, denoted by $\alpha^{* i}$. Individual's utility is a function of

\footnotetext{
${ }^{23}$ That is, $\max _{I G} V^{N}\left(Y-\left[\left(G-G^{* S}(M)\right) / M\right], G\right) \equiv V^{N d *}$.

${ }^{24}$ This analysis depends however on the strong assumption that those within the community are identical. Recall our earlier discussion that when there are large differences within each community and mobility, the equilibrium is, in general, inefficient; a unitary government might be able to internalize the externalities.
}

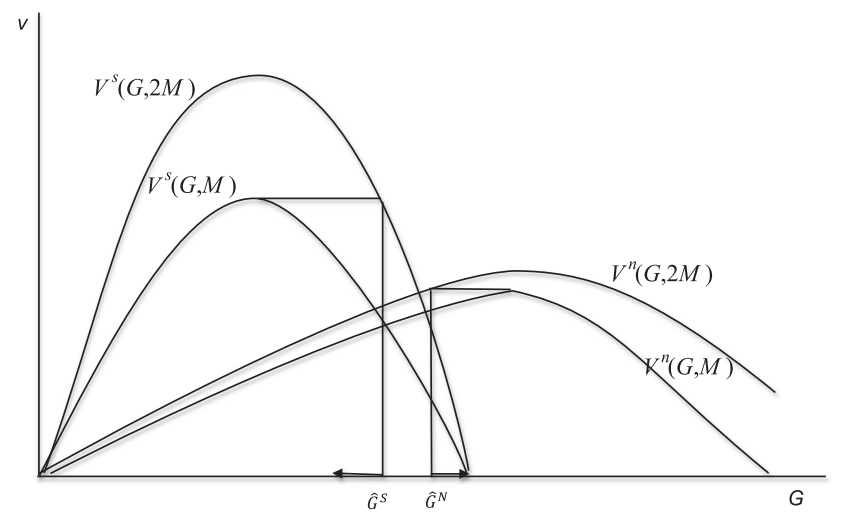

Fig. 2. If there are large enough differences in preferences, then there exists no value of $G$ such that both the North and the South are better off together than apart, under the assumption of uniform treatment.

the gap between the characteristic of the good actually supplied and the preferred type:

$V^{i}=V^{i}\left(Y-G / 2 M, G, \alpha-\alpha^{i *}\right)=v^{i}(G, 2 M, \alpha)$.

Assume the South is in the majority (by one vote), and chooses $\alpha$ to maximize its well being, so $\alpha=\alpha^{S *}$. Then, as before, we can describe the utility of those in the North and South as a function of $G$. In the case depicted in Fig. 3a, the utility of those in the North is lowered (at each $G$ ) from what it would have been had the preferred public good been provided, but even so, the North prefers more $G$ than the South. But Fig. 3b illustrates the case where the North actually gets disutility out of the public good with characteristic $\alpha^{S *}$, and so the optimal supply of the public good, from the North's perspective, is actually zero.

Now, however, if the North separates, not only can it choose for itself the level of $G$, but also its characteristic. It is now more likely that secession is desirable, i.e. that

$v^{N}\left(G^{* S}(2 M), 2 M, \alpha^{S *}\right)<v^{N}\left(G^{* N}(M), M, \alpha^{N *}\right)$.

(This is the case illustrated in Fig. 3a) It is also more likely that there is no feasible compromise, i.e. no $\{\alpha, G\}$ such that

$V^{S}(G, 2 M, \alpha)>V^{S}\left(G^{*}(M), M, \alpha^{S *}\right)$

and

$V^{N}(G, 2 M, \alpha)>V^{N}\left(G^{*}(M), M, \alpha^{N *}\right)$

That is, there is no set of values of $\{G, \alpha\}$ such that both the South and North are better off staying together and compromising on $G$ and $\alpha$. If there exists such a set of $\{G, \alpha\}$, with $S$ in the majority, $G$ will be chosen so that

$V^{N}(G, 2 M, \alpha)=V^{N}\left(G^{*}(M), M, \alpha^{N^{*}}\right)$,

that is, $\alpha$ and $G$ are chosen to maximize the well-being of the South, subject to the constraint that the North does not want to secede.

There may exist no such compromise - even with tax discrimination - if preferences differ enough. This is illustrated by the case where $\alpha$ can take on only two values, and where what the North views as a public good (say a war in Iraq), the South views as a public bad.

\subsubsection{A parametric example}

In this section, we illustrate our analysis assuming that individuals differ only with respect to their preferred type of public good. Assume we can describe the public good by a number $\alpha, 0 \leq \alpha \leq 1$, and the North's preferred characteristic is $\alpha^{N}$ while that of the South is $\alpha^{S}$. Assume that the level of utility enjoyed by an individual in the North if 

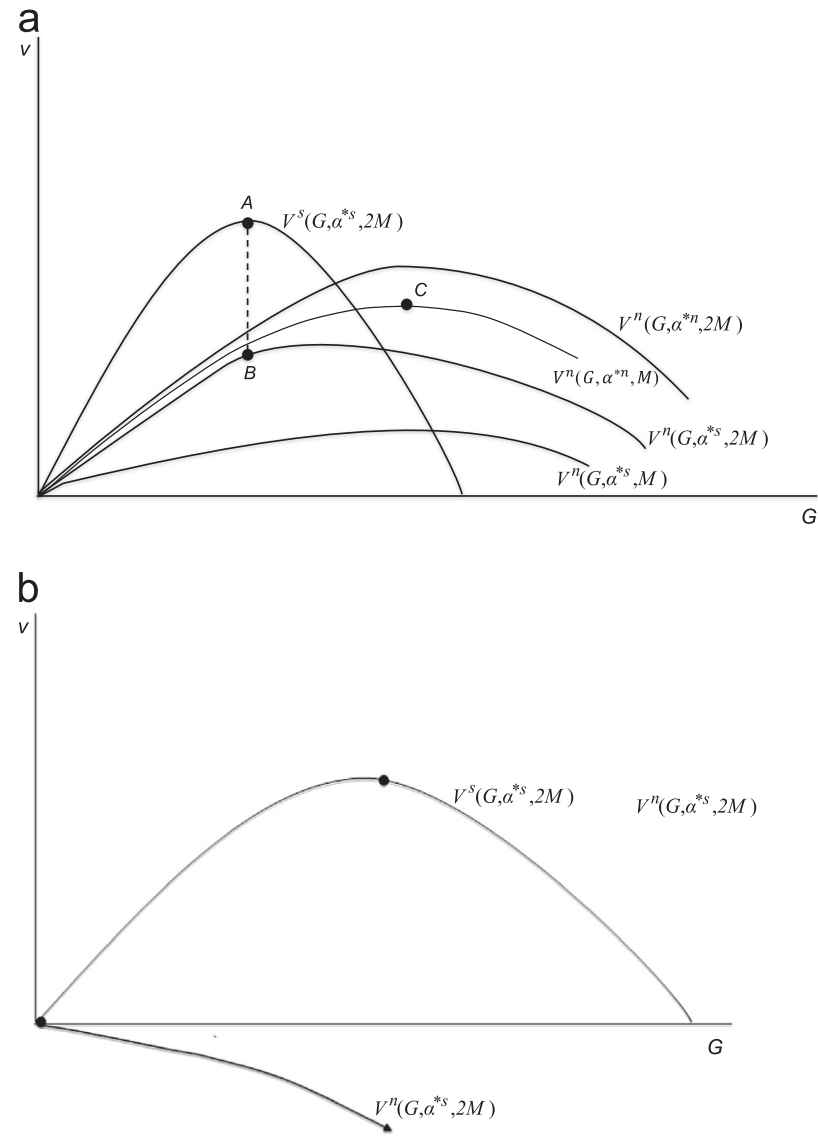

Fig. 3. (a) The South chooses a form of the public good that maximizes its utility. Even though the North would prefer a different variety, and even though the South chooses a level of public goods that is lower than the North prefers, the utility of the North is higher when the two regions remain together, simply because of the returns to scale. (b) The two regions may have very large differences in preferences, so much so that what is viewed as a good by the South is perceived as a bad by the North. Obviously, in this case, separation is desirable.

consumption is $C$ and the public good provision is described by $\{G, \alpha\}$ is given by

$U^{N}=U\left(C, G\left[1-4 k^{2}\left(\alpha^{N}-\alpha\right)^{2}\right]\right)$

that is, the value of each unit of the public good is diminished by the "distance" from the preferred type, where k represents the sensitivity of the individual to the characteristic of the public good. A similar function describes the South. All individuals have the same fixed income $Y$, and face a tax rate of $\tau$, so

$C=(1-\tau) Y$

and, normalizing the population of each region at 1 ,

$G=2 \tau Y$

Assume naturally that $\tau$ is chosen to maximize utility. Assume, as before, that the South has a bare majority, but imposes its will, both with respect to type and level of the public good. Then $\alpha=\alpha^{S}$, and the utility that the North gets from each unit of public good is

$1-4 k^{2}\left(\alpha^{N}-\alpha^{S}\right)^{2}$.

The utility is negative if

$\alpha^{N}-\alpha^{S}>1 / 2 k$

i.e. if differences in preferences are too big, then those in the North actually receive disutility from the public good. If differences are even larger, i.e. if

$\alpha^{N}-\alpha^{S}>1 / k$

then there is no compromise. ${ }^{25}$ Choosing $\alpha$ that is half way between that preferred by the North and South generates negative utility from the public good to both the North and the South.

Assume, on the other hand, that differences in preferences are not that great, but that the South imposes its preferences. Then the South will want more public goods than the North (simply because the value of each unit of the public good is higher), and it will therefore vote for a higher $G$. The optimal $G$ satisfies

$U_{C}^{S}=2 U_{G}^{S}$

On the other hand, in the devolution equilibrium each region provides its own public goods, which are assumed to be limited to its own population. ${ }^{26}$ It must pay twice the "price" for its public goods (there are half the number of people to share in the costs), but it gets an $\alpha$ that is more to its liking. If

$2\left[1-4 k^{2}\left(\alpha^{N}-\alpha^{S}\right)^{2}\right]=1$

then at any given $\tau$ (level of private consumption), in the integrated economy the level of effective public consumption is the same as in the economy with full devolution, and therefore the level of utility is the same. It follows that devolution is desirable (undesirable) if

$8^{.5} k\left|\alpha^{N}-\alpha^{S}\right|>(<) 1$,

i.e. if the differences between the two regions are large or the sensitivity to differences is large.

On the other hand, consider the compromise where

$\alpha=\left(\alpha^{N}+\alpha^{S}\right) / 2$.

The value of $\alpha$ is chosen halfway between the preferred value of each region. This would seem to be the most conducive to integration. Devolution is still desirable (undesirable) as

$2^{5} k\left|\alpha^{N}-\alpha^{S}\right|>(<) 1$

The arguments for devolution are even greater when it comes to the provision of publicly provided private goods for which there are no economies of scale, but which are provided uniformly over a region. Then, as we have noted, devolution is always desirable.

Notice that if there is a compromise between the two regions ( $\alpha$ is chosen half way between the two preferred values), because of the symmetric form of the utility function, both the North and the South agree on the tax rate. But if the North and the South differ in their preferences for public goods when optimally designed, then they will not want the same tax rate. Assume, for instance that the North's utility function is as specified above (3.12), but that of the South is given by

$U^{S}=U\left(C, \xi G\left[1-4 k^{2}\left(\alpha^{N}-\alpha\right)^{2}\right]\right)$,

where $\xi<1$. Then, with devolution, the South will want $G$ and $\tau$ to be smaller than the level preferred by the North.

If the publicly provided good is a local (regional) public good, with no spill overs from one region to the other, with each region

${ }^{25}$ That is, there is no value of $\alpha$ such that $4 k^{2}\left(\alpha^{N}-\alpha\right)^{2}<1$ and $4 k^{2}$ $\left(\alpha^{S}-\alpha\right)^{2}<1$

${ }^{26}$ Obviously, if these were true "national" public goods, each region would benefit from the public goods provided by the other region. As we noted in Section 2 we can think of there being a cost for extending the geographical reach of a public good. In the case of full devolution, each region would be unwilling to pay even that slight cost. The analysis can easily be generalized to the case where each region provides a public good which partially (fully) reaches those in the other region and or in which one region pays the other region to extend the reach of its publicly provided goods. 
choosing its own value of $\alpha$, then with $\xi=1$ there is no reason for independence (rather than just devolution). But, of course, there is no reason (within this model) against it. There are no real benefits or costs to integration. On the other hand, if $\xi<1$, even if each region gets to choose its own $\alpha$, there is a real cost to integration unless the North gets full discretion in the imposition of its tax rate, in which case (in this limited model) there is de facto independence.

In the next section, however, we provide conditions under which devolution does not suffice, even if $\xi=1$ and each region has full discretion in its choice of public goods. Independence is required.

Part II. Limitations of Devolution of Expenditures in the Absence of Devolution of Taxation

A standard model for devolution entails tax rates set by the central government, but regional governments being given discretion on how money is spent. This allows differences in local preferences to be reflected in public choices. This roughly describes the situation in the United Kingdom, where the Scottish government had discretion over expenditures on, for instance, health and education. ${ }^{27}$ In the next section, we will explain why this form of devolution will not, in general, result in an efficient allocation of publicly provided goods when there are public investment goods. In Section 5. we extend the analysis to the case where the region contemplating secession is small.

\section{Underinvestment in public goods in the absence of independence}

Assume that there is a common tax rate, $\tau$, which is used to finance the provision of public goods, but each region is allowed to choose its own public goods (with its own characteristics.) But assume that the region can choose between a publicly provided consumption good (or a local public good) and a public investment good which increases tax revenues next period, but that the tax revenue generated by the public investment is shared with the other region. We assume that the publicly provided goods are local public goods, so there are no economies of scale in providing the goods across regions. This obviously biases our results towards independence. In practice, most of the publicly provided goods which are subject to devolution are local public goods or publicly provided public goods. We continue with our parametric example; but it should be clear that it is easy to generalize the results.

Then utility in each region can be described by

$U=U^{1 j}\left(\left(1-\tau^{1}\right) Y^{1}, G_{c}^{j}\right)+U^{2 j}\left(\left(1-\tau^{2}\right) Y^{2}+\tau^{2} \rho\left(2 \tau^{1} Y^{1}-G_{c}{ }^{N}-G_{c}{ }^{S}\right) / 2\right)$

where $\rho$ is the gross return on public investments, $Y^{1}$ is first period income, $Y^{2}$ is second period income, $\tau^{1}$ is the tax rate the first period, $\tau^{2}$ is the tax rate the second period, and where $G_{c}^{j}$ is jth region's consumption (first period) of public consumption goods. Spending on public investment goods is the difference between tax revenues and spending on public consumption goods, i.e. $\tau^{2} \rho\left(2 \tau^{1} Y^{1}-G_{c}^{N}-G_{c}^{S}\right)$ is the total income generated by that investment, half of which is allocated to each of the two regions. $G_{c}^{j}$ is chosen to maximize $U$, i.e.

$\partial U^{1 j} / \partial U_{G c j}=\tau^{2} \rho\left(\partial U^{2 j} / \partial G^{2}\right) / 2$,

where $\tau^{2} \rho / 2$ is the increase in consumption of public goods in the second period as a result of the increased spending on public goods in the first period, and $\left(\partial U^{j 2} / \partial G^{2}\right)$ is the marginal utility of that increased consumption. Each region, by increasing

\footnotetext{
${ }^{27}$ In practice, matters are always more complicated. There is often discretion on the imposition of some local taxes and some restrictions on how the regional governments can spend their money.
}

consumption of public goods, gets the full benefit of the public consumption good, but pays only half the price in terms of the lost next period income from the reduced public investment. There will be too large an expenditure on public consumption goods relative to public investment goods.

With independence, utility is given by

$U=U^{1 j}\left(\left(1-\tau^{1}\right) Y^{1}, G_{c}^{j}\right)+U^{2 j}\left(\left(1-\tau^{2}\right) Y^{2}+\tau^{2} \rho\left(\tau^{1} Y^{1}-G_{c}{ }^{j}\right)\right)$.

In the symmetric equilibrium, (4.1) and (4.3) are identical, but in the case of independence, the region (now country) chooses $G_{c}^{j}$ to maximize (4.3) yielding

$\partial U^{1 j} / \partial U_{G c j}=\tau^{2} \rho\left(\partial U^{2 j} / \partial G^{2}\right)$,

i.e. the allocation to public consumption goods is now efficient. Independence is (under the stipulated conditions) always preferable to simple devolution.

The inefficiency we have noted can be corrected by not sharing tax revenue; but in this model, that is tantamount to independence. Alternatively, one can try to establish "incentive compatible" mechanisms, for instance, by taxing the additional revenue arising from public investment (if one can ascertain what that is) only in the region which makes the public investment. We then maximize

$U=U^{1 j}\left(\left(1-\tau^{1}\right) Y^{1}, G_{c}{ }^{j}\right)+U^{j 2}\left(\left(1-\tau^{2}\right) Y^{2}+\tau^{2} \rho\left(\tau^{1} Y^{1}-G_{c}{ }^{J}\right)\right)$,

which yields the same allocation as (4.3), with the optimality condition given by (4.4).

\section{Small regions}

So far, we have considered two regions of equal size. The argument for devolution and independence for a small region is slightly different.

\subsection{Publicly provided consumption goods}

If there are economies of scale, e.g. associated with a pure public good, the economies of scale will (in the limit, of an arbitrarily small region) always outweigh the "tailoring" effect, except when the disparity in preferences is very large. But as we have noted, a large fraction of public expenditures is for publicly provided private goods and for local/regional public goods, for which the economies of scale are less significant, or may not be there at all.

There still can exist important cross border externalities: with devolution, the small region can free ride on the public investments made nationally, and the tax revenue benefits of public investments made by the small region are largely not captured by the region. If there is only one small region, the externalities (especially the former one) may not matter much; but in a nation consisting of many small regions, the aggregate consequences can be serious. Especially in the absence of strong economies of scale, the inability to effectively internalize these externalities means that independence may be preferable to devolution.

Assume there is a single small region. The political equilibrium for the nation will then reflect the preferences of the dominant region. Let us assume that the South is the dominant region. To continue with the model of Section 3, $\alpha^{*}=\alpha^{S}$, and $\tau$ is set to maximize ${ }^{28}$

$U^{S}=U((1-\tau) Y, \tau Y)$

${ }^{28}$ We continue with the normalization that the population in the South is unity. This formulation assumes that the North is miniscule relative to the South. The analysis for the more general case is straightforward. 
so that

$U_{C}^{S}=U_{G}^{S}$

Utility in the North is now

$U^{N}=U\left(C, G\left[1-4 k^{2}\left(\alpha^{N}-\alpha^{S}\right)^{2}\right]\right)$.

We denote (as in Section 2) the average returns to scale in the public good by $\beta, 0 \leq \beta \leq 1$, and assume that the ratio of the population of the North to the South is $M$. We continue with the normalization that the population of the South is unity. Then with integration and a tax rate of $\tau$, and a pure public good $(\beta=1)$, the public good supply (per capita) in the North is $(M+1) \tau Y$. If the good is a publicly provided private good, then the public good supply (per capita) in the North is $\tau$ Y. More generally, for a mixed public good, the public good supply is approximated by $(M \beta+1) \tau Y$.

Hence at any given $\tau$, utility would be higher with devolution if

$\left\{1-4 k^{2}\left(\alpha^{N}-\alpha^{S}\right)^{2}\right\}(M \beta+1) \geq 1$

or

$\beta \leq\left\{4 k^{2}\left(\alpha^{N}-\alpha^{S}\right)^{2}\right\} /\left[1-4 k^{2}\left(\alpha^{N}-\alpha^{S}\right)^{2}\right\} M \equiv \beta^{*}$.

If preference differences are not too large $\left(\left|\alpha^{N}-\alpha^{S}\right|<1 / 2 k\right)$, then with a large enough population, devolution is never desirable. But for any fixed $M$, if the returns to scale are small enough, i. e. $\beta \leq \beta^{*}$, devolution is always desirable. ${ }^{29}$

If preference differences are large enough, what is a public good in the South is viewed as a public bad in the North, and devolution is always desirable. ${ }^{30}$

\subsection{Public investment}

Assume now that there is a public investment good and there are no differences in preferences. Again, the South effectively sets the tax rate to maximize its utility, while, if $M$ is small enough, the North, not recapturing any of the benefits of its investments in public goods, only spends its public funds on consumption (under devolution.) The North free rides on the public investment of the South and would never be better off with independence.

But now assume that the North and the South have different preferences, so that the South puts more emphasis on current consumption of public goods. We write the (reduced form) utility function of the North and South as

$U^{N}=U^{N 1}\left(C^{N 1}, \psi^{N} G^{N}{ }_{c}\right)+U^{N 2}\left(C^{N 2}\right)$,

$U^{S}=U^{S 1}\left(C^{S 1}, \psi^{S} G_{c}^{S}\right)+U^{S 2}\left(C^{S 2}\right)$,

where $\psi^{N} \leq 1$ and $\psi^{S} \geq 1$. Then it is easy to show that the consumption of public goods the first period increases with $\psi^{S}$, and second period income (consumption) decreases. Take the limiting case, where all of the public good expenditure (as determined by the South) goes into consumption. Then the North's utility with devolution is approximately (assuming that the small region recaptures essentially none of the incremental returns from its investments)

$U^{N}=U^{N 1}\left(\left(1-\tau^{1}{ }_{d}\right) Y, \psi^{N} \tau^{1}{ }_{d} Y\right)+U^{N 2}\left(Y^{2}\left(1-\tau^{2}\right)\right)$,

${ }^{29}$ Note that with devolution, the south will set its tax rate at the same rate as the North if the publicly provided good is a privately provided public good, but otherwise, it will set a lower tax rate and enjoy a lower supply of public goods and a higher supply of private goods. Hence (5.5) is a sufficient condition for devolution, but not a necessary condition.

${ }^{30}$ As we noted earlier, to many, perhaps most, in Scotland, military expenditures, e.g. on a war in Iraq, may have been a public bad rather than a public good. (in the obvious notation where $t_{d}^{1}$ is the first period tax rate under devolution, where the tax rate is set by the South, with revenues shared proportionately with the North).

With independence, the North's utility is given by the maximized value (with respect to $\tau_{I}^{1}$ and $G_{c}^{1}$ where $\tau_{I}^{1}$ is the first period tax rate under independence, where now the tax rate is set by the North) of

$U^{N}=U^{N 1}\left(\left(1-\tau_{I}^{1}\right) Y, \psi^{N} G^{1}{ }_{c}\right)+U^{N 2}\left(\left(1-\tau^{2}\right) Y^{2}+\tau^{2} \rho\left(\tau_{I}^{1} Y^{1}-G_{C}{ }^{l}\right)\right)$,

taking for the moment $\tau^{2}$ as fixed. ${ }^{31}$ It should be apparent that (5.9) always exceeds (5.8), except in a corner solution, where $\psi^{\mathrm{N}}$ is so large or $\rho$ is so small that the North spends all of its public expenditures on consumption. Even then, (5.9) will be larger than (5.8) because $\tau_{I}^{1}$ is chosen to reflect the North's preferences for public goods, not the South's. Thus, there is a critical magnitude of differences in preferences (differences between $\psi^{S}$ and $\psi^{N}$ ) such that independence is preferred to devolution. If preferences (judgments about returns to public investments) between the small region and the rest of the nation are large enough, independence is preferred; the gains from tailoring public spending to one's preferences and judgments outweigh the potential free rider benefits under devolution.

\section{Concluding comments}

This paper was partly inspired by my earlier work with Richard Arnott on externalities and public goods. But, as I noted in the introduction, it was also partly inspired by the debate in 2014 over Scottish independence. There had already been considerable devolution. What were the benefits and costs to independence, to going beyond the level of devolution which existed at the time, especially in the context of the EU, where there would presumably continue to be free mobility of goods, people, and capital, so that all, or least most, of the economies of scale and scope in private production and consumption could be retained?

Here, we note that while some of the debate did center on two of the issues raised in this paper, four other topics also played a role. There was considerable focus on differences in preferences, especially for what we have referred to as privately provided public goods, where economies of scale are not significant (so that the cost of independence would not be significant.) Scotland and England had been going in markedly different directions. Scotland seemed to be aspiring to create a Nordic style social democratic state. England seemed to be aspiring to create an American style society, marked by high levels of social, political, and economic inequalities. Scotland was providing free university tuition; England was raising tuition fees. England was taking actions that were seen as undermining the country's National Health Service (NHS), yet the principle of access to health care for all, had strong support within Scotland.

In the case of the perhaps most important pure public good, expenditures on the military, differences in attitudes were so great that what was viewed as a public good in England (exemplified by the participation in the War in Iraq) was widely viewed as a public bad in Scotland. ${ }^{32}$

The problems with partial devolution that was the focus of Part II of the paper were also important: the expenditures on education were viewed as investments, as were other expenditures on children and those on industrial policies. The Scottish government

\footnotetext{
${ }^{31}$ But of course, with independence, the South will have full discretion to set the tax rate, and will choose it to maximize the utility of its citizens, providing a further benefit from independence.

32 Of course, in both England and Scotland there was far from unanimity.
} 
was keenly aware that it would reap little of the returns from these investments.

Of the four other issues that received prominence, two were technical issues involving economics - but in which there were considerable misunderstandings.

There was a heated debate about the directions of net transfers whether Scotland was subsidizing the rest of the UK or being subsidized, and therefore whether independence, which would halt the flow of subsidies, would increase or decrease the well-being of Scotland. In the end, the numbers in either direction seemed small compared to other potential costs or benefits of independence and the risks associated with al arrangements.

The most complex debate surrounded the monetary system post independence. A monetary policy extending over multiple jurisdictions can be viewed as a public good provided uniformly across those jurisdictions - a public good for which tastes can differ markedly, so there can be marked differences in views about the form that such policies should take. Indeed, it is an example of a public good that some might view as a "good", and others as a "bad". (Tight monetary policy might have benefits to some jurisdictions/regions and large costs for others.) The literature on optimal currency areas attempts to spell out the conditions under which a shared currency (the common provision of this public good) might be desirable.

It had originally been proposed that Scotland and the remainder of Great Britain remain within a monetary union. This was done to minimize the transition uncertainty. The subsequent eurocrisis, highlighting the problems of making a currency union work, cast a damper over this idea. ${ }^{33}$ But a central problem with the euro was that the differences among the eurozone countries were enormous compared to that between Scotland and England. (In terms of the formalisms of the models presented here, the differences in "preferences" with respect to this particular public good were relatively small.) The conditions that Mundell (1961) had set forth for an optimal currency area were more clearly nearly satisfied.

When it was suggested that England might refuse to agree to a monetary union, one response was that Scotland could use the pound sterling as its currency even without the permission of UK (as Ecuador and Panama use the dollar.) Of course, this would entail Scotland not enjoying the seigniorage, but that was likely limited in any case (especially once one considered that Scotland would be entitled to but a small share of the entire value of the seigniorage for the UK.) And it would mean that Scotland would have no say in the determination of monetary policy. But, again, given its relatively small size, its role in monetary policy was already limited.

It might, in any case, be better for Scotland to have its own currency-as many other small countries do. Some (like Denmark) are pegged; some (like Iceland) are floating. In short, monetary institutions do make a difference-poorly designed institutions like those of the eurozone can have a disastrous effect on the economy. But there are many monetary arrangements that can work. There was no reason to believe that Scotland could not design a set of monetary arrangements that would work for its economy. Indeed, this was another public good where preferences differed significantly, making the case for independence even greater. ${ }^{34}$

Two other issues, though, played an important role in the debate, one which is associated with virtually any major institutional reform, and both of which should be the focus of more research going forward. The critics of independence emphasized the risks: there were uncertainties associated with a new political institutional arrangement, and not surprisingly, risk-averse individuals focused on

\footnotetext{
33 See Krugman (2014).

${ }^{34}$ There is an increasing recognition that the conduct of monetary policy can affect the distribution of income. (See, e.g. Stiglitz, 2012). Different polities have different attitudes towards inequality.
}

the downside potential. Some banks threatened to move their headquarters, perhaps out of fear that the Scottish government would be less captured by the financial sector than that in Westminster. But defenders of independence responded that this might even be positive: scotland could design a regulatory regime that would facilitate the creation of a financial sector more focused on serving its citizens and its economy than on speculation, market exploitation, etc. And net, the financial sector as structured had been a drain, given the huge expenditures that had been required by the bail-outs. Better regulation might reduce the risks posed to the rest of society by the financial sector.

Most importantly, there were large risks whether Scotland remained within the UK or not. The UK had an upcoming referendum about leaving the EU. If Scotland had to choose between being part of the EU or in a union with England, all the arguments about economies of scale and scope suggested that the former was far preferable to the latter. What would happen if the politics of England continued to drift towards the right - with larger and larger differences between the policies which would have been preferred by Scottish citizens? What would happen if England continued its course of unbalanced growth, with the counties in the South doing so much better than the rest of the country?

Inevitably, major changes in institutional arrangements such as that posed by Scottish independence bring countries into unchartered territory, often where there is limited relevant evidence from previous similar experiments. Standard economic models, resting on well-defined beliefs, typically based on rational expectations, provide little guidance in these situations.

The second set of issues relates to national identity, social cohesion, and societal performance, subjects to which economists and other social scientists are just beginning to devote more attention. ${ }^{35}$ There is some evidence that firms in which there is more social cohesion perform better ${ }^{36}$; so too, there is increasing evidence that societies with greater social cohesion - trust, social capital - perform better ${ }^{37}$ It is possible that independence could foster a great sense of identity and social cohesion, and especially so during the nation-building stage. ${ }^{38}$

In the end, it appears that voters in Scotland were more influenced by the possible down-side risks than by the possibilities of a national rejuvenation, of a second Scottish Enlightenment, with a new set of aspirations and renewed sense of identity that independence might have brought about. The campaign became, however, distracted on some second order issues, and even the more mundane economic issues that we have addressed here - the balancing out of returns to scale, tailoring of public goods to societal preferences, and uninternalized externalities - were given short shrift.

Ongoing debates around the world make it clear that questions surrounding the creation of political entities will continue to be at the forefront of public discussions. In many, perhaps most, countries. the political debate will center around political issues, included those that were central to the Scottish debate. This paper has provided a broad framework within which one can analyze the economics, the benefits and costs of devolution, independence, and integration. Within that framework, we have demonstrated a range of conditions under which devolution enhances societal welfare, and in which devolution of expenditures may not suffice - independence may be preferable even

\footnotetext{
${ }^{35}$ These subjects have flourished particularly with the increasing importance associated with behavioral economics. (See, for instance, Akerlof and Kranton, 2010; World Bank, 2015).

${ }^{36}$ For a discussion of some of the evidence and references, (see

37 See Algan and Cahuc (2013) and Easterly et al. (2006), and the references cited there.

${ }^{38}$ But even here, it is important to observe that there were differences in preferences within Scotland. Some saw their sense of identity as connected with being in the UK including many who had migrated from south of the border.
} 
in the presence of the returns to scale associated with the provision of public goods when there are important public investments.

\section{Appendix. Joint papers with Richard Arnott}

"Aggregate Land Rents, Expenditure on Public Goods and Optimal City Size," Quarterly Journal of Economics, 93(4), November 1979, pp. 471-500.

"Aggregate Land Rents and Aggregate Transport Costs," Economic Journal, 91(362), June 1981, pp. 331-347.

"Labor Turnover, Wage Structure \& Moral Hazard: The Inefficiency of Competitive Markets,", Journal of Labor Economics, 3(4), October 1985, pp. 434-462.

Moral Hazard and Optimal Commodity Taxation," Journal of Public Economics, 29, 1986, pp. 1-24.

"Safety, User Fees, and Public Infrastructure," in: Transportation Deregulation and Safety, Conference Proceedings, The Transportation Center, Northwestern University, June 1987, pp. 411-445.

The Basic Analytics of Moral Hazard," Scandinavian Journal of Economics, 90(3), 1988a, pp. 383-413.

"Implicit Contracts, Labor Mobility and Unemployment," (jointly with A. Hosios), American Economic Review, 78(5), December 1988b, pp. 1046-1066.

"Randomization with Asymmetric Information," Rand Journal of Economics, 19(3), Autumn 1988c, pp. 344-362.

Congestion Pricing to Improve Air Travel Safety," in Transportation Safety in an Age of Deregulation, L.N. Moses and I. Savage (Eds.), Oxford University Press, 1989, pp. 167-185.

"The Welfare Economics of Moral Hazard," in: Risk, Information and Insurance: Essays in the Memory of Karl H. Borch, H. Louberge (Ed.), Norwell: Kluwer Academic Publishers, 1990, pp. 91-122.

"Moral Hazard and Non-Market Institutions: Dysfunctional Crowding Out or Peer Monitoring," American Economic Review, 81(1), March 1991, pp. 179-190.

"Information and Economic Efficiency," (jointly with B. Greenwald), Information Economics and Policy, 6(1), March 1994, pp. 7788.

"Equilibrium in Competitive Insurance Markets with Moral Hazard," in The Selected Works of Joseph E. Stiglitz Volume II: Information and Economic Analysis: Applications to Capital, Labor, and Product Markets, Oxford: Oxford University Press, 2013, pp. 660-689. Originally Princeton University Discussion Paper 4, 1987. Also NBER Working Paper 3588, 1991.

"Price Equilibrium, Efficiency, and Decentralizability in Insurance Markets," in The Selected Works of Joseph E. Stiglitz Volume II: Information and Economic Analysis: Applications to Capital, Labor, and Product Markets, Oxford: Oxford University Press, 2013, pp. 632-659. Originally NBER Working Paper 3642, 1991.

\section{References}

Akerlof, George A., Kranton, Rachel E., 2010. Identity economics: how our identities shape our work, wages, and well-being. Princeton University Press, Princeton, New Jersey.

Algan, Yann, Cahuc, Pierre, 2013. Trust, Growth and Well-being: New Evidence and Policy Implications. IZA Discussion Papers 7464, Institute for the Study of Labor (IZA).

Arnott, Richard, 1998. William Vickrey: contributions to public policy. Int. Tax Public Financ. 5, 93-113.

Arnott, Richard, Stiglitz, Joseph E., 1979. Aggregate land rents, expenditure on public goods and optimal city size. Q. J. Econ. 93 (4), 471-500.

Arnott, Richard, Stiglitz, Joseph E., 1988. The basic analytics of moral hazard. Scand. J. Econ. 90 (3), 383-413.

Arnott, R., J.E., Stiglitz, 1990. The welfare economics of moral hazard. In: Louberge, H. (Ed.), Risk, Information and Insurance: Essays in the Memory of Karl H. Borch. Kluwer Academic Publishers, Norwell, pp. 91-122, Also NBER Working Paper 3316

Arnott, Richard, Greenwald, Bruce, Stiglitz, Joseph E., 1994. Information and economic efficiency. Inf. Econ. Policy 6 (1), 77-88.
Atkinson, A., Stiglitz, Joseph E., 1980. Lectures on Public Economics. McGraw Hill, New York.

Bowie, Karin, 2007. Scottish Public Opinion and the Anglo-Scottish Union, 16991707. Boydell \& Brewer Ltd, Suffolk.

Dixit, Avinash, Stiglitz, Joseph E., 1977. Monopolistic competition and optimum product diversity. Am. Econ. Rev. 67 (3), 297-308.

Faguet, Jean-Paul Pöschl, Caroline, August 2015. Is Decentralization Good for Development? Perspectives from Academics and Policy Makers, Oxford University Press, Oxford, UK.

Flatters, F., Henderson, V., Mieszkowski, P., 1974. Public goods, efficiency, and regional fiscal equalization. J. Public Econ. 3, 99-112.

George, Henry, 1879. Progress and Poverty. Robert Schalkenbach Foundation, New York (Reprinted in 1929).

Herman, Arthur, 2001. The Scottish enlightenment: the Scot's invention of the Modern World. Harper Perenniel, London.

Hotelling, Harold, 1929. Stability in Competition. Econ. J. 39 (153), 41-57.

Inge, Kaul, Grunberg, Isabelle, Stern, Marc A., 1999. Global Public Goods: International Cooperation in the 21st Century, United Nations Development Programme. Oxford University Press, New York.

Krugman, Paul, 2014. Scots, what the heck? New York Times, September 7. 〈http:/ www.nytimes.com/2014/09/08/opinion/paul-krugman-scots-what-the-heck. html? r $=0\rangle$ (accessed 05.11.14).

Lizzeri, Alessandro, Persico, Nicola, 2001. The provision of public goods under alternative electoral incentives. Am. Econ. Rev. 91 (1), 225-239.

Mundell, Robert A., 1961. A theory of optimum currency areas. Am. Econ. Rev. 1961, 657-665.

Oates, Wallace, 1999. An essay on fiscal federalism. J. Econ. Lit. 37 (3), 1120-1149.

Persson, Torsten, Roland, Gerard, Tabellini, Guido, 2000. Comparative politics and public finance. J. Polit. Econ. 108 (6), 1121-1161.

Qian, Yingyi, Roland, Gerard, 1998. Federalism and the soft budget constraint. Am. Econ. Rev. 88 (5), 1143-1162.

Samuelson, Paul A., 1954. The pure theory of public expenditure. Rev. Econ. Stat. 36 (4), 387-389.

Serck-Hanssen, J., 1969. The optimal number of factories in a spatial market. In: Bos, H. (Ed.), Towards Balanced International Growth. North-Holland, Amsterdam, pp. 269-282.

Starrett, D., 1974. Principles of optimal location in a large homogeneous area. J Econ. Theory 9, 418-448.

Stiglitz, Joseph E., 1974. Demand for education in public and private school systems. J. Public Econ. 2, 349-386.

Stiglitz, Joseph E., 1977. Theory of local public goods. In: Feldstein, M.S., Inman, R.P. (Eds.), The Economics of Public Services, 1977. MacMillan Press, London, pp. 274-333 (Paper presented to IEA Conference, Turin, 1974.)

Stiglitz, Joseph E., 1983a. The Theory of local public goods twenty-five years after tiebout: a perspective. In: Zodrow, G.R. (Ed.), Local Provision of Public Services: The Tiebout Model After Twenty-Five Years. Academic Press, New York, pp. 17-53.

Stiglitz, Joseph E., 1983b. Public goods in open economies with heterogeneous individuals. In: Thisse, J.F., Zoller, H.G. (Eds.), Locational Analysis of Public Facilities. North-Holland, Amsterdam, pp. 55-78.

Stiglitz, Joseph E., 1986a. Toward a more general theory of monopolistic competition. In: Peston, M., Quandt, R. (Eds.), Prices, Competition, and Equilibrium. Philip Allan/Barnes \& Noble Books, Oxford, pp. 22-69.

Stiglitz, Joseph E., 1986b. Economics of the Public Sector. W.W. Norton, New York (subsequent editions, 1988, 2000).

Stiglitz, Joseph E., 1995, The Theory of International Public Goods and the Architecture of International Organizations. Background Paper No. 7. Third Meeting, High Level Group on Development Strategy and Management of the Market Economy, UNU/WIDER, Helsinki, Finland, July 8-10, 1995.

Stiglitz, Joseph E., 1998. IFIs and the provision of international public goods. In: European Investment Bank. pp. 116-134 (Cahiers Papers, 3(2)).

Stiglitz, Joseph E., 1999. Knowledge as a global public good. In: Kaul, Inge, Grunberg, Isabelle, Stern, Marc A (Eds.), Global Public Goods: Internationa Cooperation in the 21st Century. Oxford University Press, New York pp. 308-325 (United Nations Development Programme).

Stiglitz, Joseph E., 2007. Global public goods and global finance: does globa governance ensure that the global public interest is served. In: Touffut, JeanPhilippe (Ed.), Advancing Public Goods. Edward Elgar Publishing, Great Britain, pp. 149-164.

Stiglitz, Joseph E., 2012. The price of inequality: how today's Divided society endangers our future. W.W. Norton, New York.

Stiglitz, Joseph E., 2015. Selected Works, vol. III. Oxford University Press, Oxford (forthcoming).

Tiebout, Charles M., 1956. A pure theory of local expenditures. J. Polit. Econ. 1956 416-424.

Vickrey, W., 1977. The city as a firm. Originally published. In: Martin, S., Feldstein, Inman, Robert F. (Eds.), The Economics of Public Services. Proceedings of a Conference Held by the International Economics Association at Turin. MacMillian, London, pp. 339-349 (Wiley, New York, 1977. Available in William Vickrey, (1994), Public Economics: Selected Papers by William Vickrey, Cambridge University Press, Cambridge, UK).

William, Easterly, Ritzen, Jozef, Woolcock, Michael, 2006. Social cohesion, institutions, and growth. Econ. Polit. 18 (2), 103-120.

World Bank, 2015, World Development Report: Mind, Society, and Behavior. 